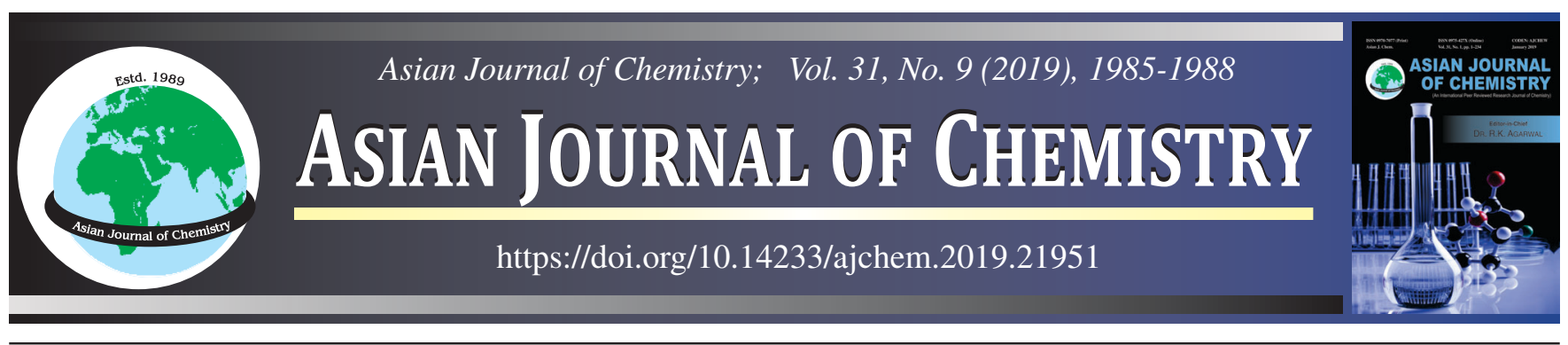

\title{
Validated UV-Vis Spectrophotometric Determination of Andrographolide in Herbal Nano-Preparation
}

\author{
Indah Hairunisa ${ }^{1}$, Muhammad Da'ín ${ }^{2}$, ERindyah Retno Wikantyasning ${ }^{2}, *$, \\ Andhika Rizky Gilang Mahaputra ${ }^{2}$, Normaidah Normaidah ${ }^{3}$ and Mohd Fadzelly Abu BaKar ${ }^{4}$
}

${ }^{1}$ Faculty of Health and Pharmacy, Universitas Muhammadiyah Kalimantan Timur, Samarinda 75243, Indonesia

${ }^{2}$ Faculty of Pharmacy, Universitas Muhammadiyah Surakarta, Kartasura, Sukoharjo 57162, Indonesia

${ }^{3}$ Faculty of Mathematics and Natural Science, Universitas Lambung Mangkurat, Banjarbaru, 70714, Indonesia

${ }^{4}$ Faculty of Applied Sciences and Technology, Universiti Tun Hussein Onn Malaysia (UTHM), 84600 Muar, Johor, Malaysia

*Corresponding author: E-mail : erindyah.rw@ums.ac.id

Received: 23 January 2019;

Accepted: 19 April 2019;

Published online: 31 July 2019;

AJC-19486

\begin{abstract}
Determination of major bioactive compounds in polyphyto-formulation is important for production of standardized herbal products. A fast, simple and inexpensive method for detection and quantification of andrographolide concentration in nanoemulsion preparations containing a combination of Andrographis paniculata (Burm f.) Ness. and Phyllanthus niruri L. has been developed. Detection and quantification were carried out using UV-vis spectrophotometry analysis with picric acid reagent and $\mathrm{NaOH}(8: 2)$ in methanol solvents, read at maximum wavelength $479 \mathrm{~nm}$ with 22 min of incubation time. Validation was done by determine the parameters such as linearity, intra and interday precision, accuracy, limit of detection (LOD) and limit of quantification (LOQ). The results obtained showed linearity with $r=0.9945(y=0.0109 x-0.2066)$ in the range of $30-80 \mu \mathrm{g} / \mathrm{mL}$. The accuracy (recovery) varied in the range of 97.15 to $104.42 \%$ Percentage of relative standard deviation (\% RSD) for precision and intermediate precision value were 3.23 and $3.02 \%$ with LOD value $211 \mu \mathrm{g} / \mathrm{mL}$ and the LOQ $705 \mu \mathrm{g} / \mathrm{mL}$. As a conclusion, this method is suitable to detect andrographolide content in herbal nano-preparation
\end{abstract}

Keywords: Andrographis paniculata, Phyllanthus niruri, Spectrophotometry, Andrographolide, Nanoemulsion.

\section{INTRODUCTION}

Validation is a concept to ensure that a method used to determine the quality of the medicinal ingredients and the right and available drug preparations proven effectiveness and reproducibility [1].

The large number of medicinal plants in Indonesia encourages the pharmaceutical industry to develop the new and advance formulations to be able to increase the bioavailability of medicinal plants based product. The most important thing in the formulation of a phytopharmaceutical product is that the product contain standardized phytochemical from medicinal plants. Andrographis paniculata (Burm f.) Ness. or locally known as Sambiloto in Indonesia has been traditionally used to treat various diseases. This plant has been shown to display antidiabetic activity [2-5]. This plant also display potent antioxidants activity [6-8]. Phyllanthus niruri L. or locally known as Meniran in Indonesia also has been used widely in India, China and Malaysia. Phyllanthus niruri is ethnobotanically used to treat hepatitis, dysentery and rheumatism. The activity of Phyllanthus niruri as a source of antioxidants has been scientifically shown [9], in addition to other activities such as antibacterial, antidiabetic and anticancer [10-12].

Previous studies have been carried out to validate the content of andrographolide from A. paniculata extract. Da'i et al. [13] studied the validated method to determine A. paniculata polyherbal mixture using RP-HPLC. Manasa and Suneetha [14] developed the method to determine the content of andrographolide levels using a UV-Vis spectrophotometer. The result of this study showed good validation results for andrographolide levels in polyherbal mixture.

The purpose of this study was to validate the method for determination of andrographolide levels in nanoemulsion preparations containing a combination of Andrographis

This is an open access journal, and articles are distributed under the terms of the Attribution 4.0 International (CC BY 4.0) License. This license lets others distribute, remix, tweak, and build upon your work, even commercially, as long as they credit the author for the original creation. You must give appropriate credit, provide a link to the license, and indicate if changes were made. 
paniculata and Phyllanthus niruri extract using a UV-Vis spectrophotometer.

\section{EXPERIMENTAL}

Dried herb of Andrographis paniculata was bought from the local herbal shop, Solo, Indonesia, while Phyllanthus niruri was purchased from the wet market (Pasar Gede) Solo, Indonesia. $P$. niruri was then dried under indirect sunlight for 3 days.

Sample extraction: Dried Andrographis paniculata and Phyllanthus niruri plants were grounded into powder using dry blender to get a uniform size. To eliminate chlorophyll, the samples were then soaked with petroleum ether (Sigma-Aldrich) in the ratio of 1:5 for A. paniculata and 1:7 for P. niruri. Then the mixture was filtered and the residue was dried for overnight. Dried residue were macerated using $70 \%$ ethanol (Merck) for 5 days, while stirring occasionally. Then the filtrate was evaporated with a vacuum rotary evaporator (Buchi) until thick extract was obtained.

Preparation of nanoemulsion: Nanoemulsion samples were prepared by mixing SNEDDS (self nanoemulsion drug delivery system) into water with a water and SNEDDS ratio (2:1). Then the solution was homogenized using a magnetic stirrer for $10 \mathrm{~min}$ at medium speed without heating.

Stock and working solutions: A solution of andrographolide stock was prepared at concentration of $500 \mu \mathrm{g} / \mathrm{mL}$ (solution A). For accuracy study, a solution of andrographolide stock (in methanol) was prepared at concentration of $5 \mathrm{mg} / \mathrm{mL}$ (solution B). Solution $\mathrm{C}$ was prepared by mixing $1 \%$ picric acid in water and $10 \% \mathrm{NaOH}$ in water. Ratio of picric acid and $\mathrm{NaOH}$ was 8:2. All the solutions were prepared fresh prior to experiments.

\section{Optimization of experimental conditions}

Determination of operating time: The operating time was determined by mixing $0.4 \mathrm{~mL}$ of solution A with $2.5 \mathrm{~mL}$ of solution $\mathrm{C}$ then made up the volume of $5 \mathrm{~mL}$ with methanol. The solution is read after every $2 \mathrm{~min}$ at $481 \mathrm{~nm}$.

Determination of maximum wavelength: The maximum wavelength is determined by mixing $0.4 \mathrm{~mL}$ of solution $\mathrm{A}$ with $2.5 \mathrm{~mL}$ of solution $\mathrm{C}$ then made up the volume of $5 \mathrm{~mL}$ with methanol. The solution is read after every $2 \mathrm{~min}$ at $481 \mathrm{~nm}$. The solution is read again after incubation for $22 \mathrm{~min}$. From the results, maximum wavelength $\left(\lambda_{\max }\right)$ was found to be $479 \mathrm{~nm}$.

Andrographolide standard curve: Andrographolide concentration was prepared at different concentration from 30 to 80 $\mu \mathrm{g} / \mathrm{mL}$. Then each concentration was analyzed using a UV-Vis spectrophotometer at operating time and maximum $\lambda_{\max }=479$ $\mathrm{nm}$. The absorbance obtained is a linear regression equation with $\mathrm{X}$ axis as the concentration and $\mathrm{Y}$ axis as absorbance.

Preparation of sample of analysis: Nanoemulsion (20 $\mu \mathrm{L})$ was mixed with $1980 \mu \mathrm{L}$ methanol. The sample was left to incubate for $5 \mathrm{~min}$. Then $0.5 \mu \mathrm{L}$ of sample was mixed with $2.5 \mathrm{~mL}$ of solution $\mathrm{C}$ and made up the volume of $5 \mathrm{~mL}$ with methanol. After $22 \mathrm{~min}$, the solution is read at $\lambda_{\max }=479 \mathrm{~nm}$ using a UV-Vis spectrophotometer.

Preparation of Andrographis paniculata and Phyllanthus niruri extracts nanoemulsion: A $100 \mathrm{mg}$ of A. paniculata and $P$. niruri extracts were mixed with $5 \mathrm{~mL}$ of methanol. The mixture was allowed to sonicated for $10 \mathrm{~min}$. The sample was allowed to rest for $5 \mathrm{~min}$, then supernatant is taken and filtered using microphore. Then the sample $(25 \mu \mathrm{L})$ was mixed with $2.5 \mathrm{~mL}$ of solution $\mathrm{C}$ and made up the volume of $5 \mathrm{~mL}$ with methanol. After $22 \mathrm{~min}$, the solution is read at $\lambda_{\max }=479 \mathrm{~nm}$ using a UV-Vis spectrophotometer.

\section{Determination of validation parameters}

Intra-day and inter-day precision: Intra-day precision was performed by reading six replicates at the same concentration in the same day. Inter-day precision was made by conducting experiment at different days. The acceptance criteria is the RSD value less than $5 \%$.

Linearity: Linearity was performed by reading from six different concentration in the range of $30-80 \mu \mathrm{g} / \mathrm{mL}$. The acceptance criteria is the $\mathrm{R}$ value more than 0.98 .

Accuracy: Accuracy is performed by standard addition method by adding 3 series of concentration levels, $80 \%$ (596 $\mu \mathrm{g} / \mathrm{mL}), 100 \%(746 \mu \mathrm{g} / \mathrm{mL}), 120 \%$ ( $895 \mu \mathrm{g} / \mathrm{mL})$. Each series of levels were replicated thrice. The acceptance criteria is the recovery value in range $95-105 \%$.

Limit of detection (LOD) and Limit of quantification (LOQ): Andrographolide standard curve was prepared using different concentrations $(30-80 \mu \mathrm{g} / \mathrm{mL})$.

\section{RESULTS AND DISCUSSION}

Optimization of wavelength and operating time: Andrographolide in polyherbal formulation can be determined using spectrophotometry analysis based in the presence of chromophore and auxochrome groups in the compound. Therefore, it is necessary to add picric acid in alkaline condition to form andrographolide complex which is orange in colour (Scheme-I). From the optimization results a value of $\lambda$ maximal of $479 \mathrm{~nm}$ and operating time for $22 \mathrm{~min}$ (Fig. 1) were obtained.

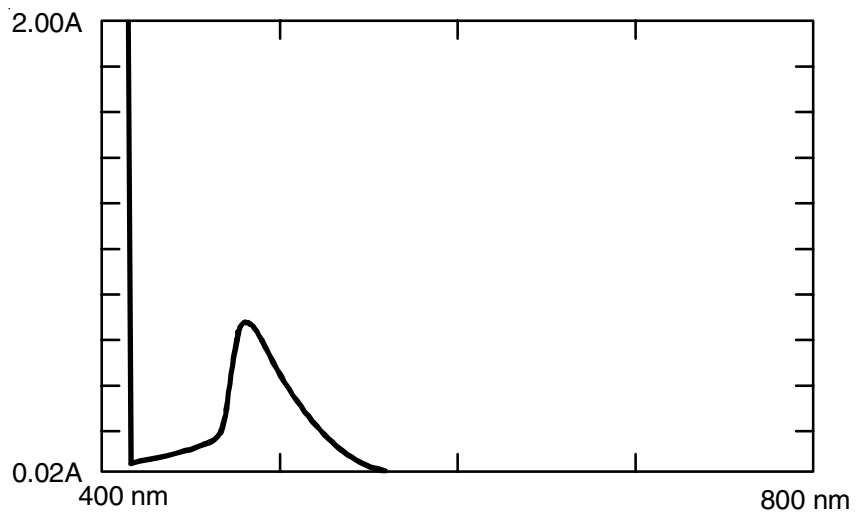

Fig. 1. Spectra of standard andrographolide absorption; Andrographolide level was analyzed using UV-vis spectrophotometer in a wavelength range of 400-800 nm. OT 22 min with $\lambda_{\max } 479 \mathrm{~nm}$

Linearity: Linearity between the concentration of andrographolide and absorbance was calculated based on a series of concentrations of ranging from 30 to $80 \mu \mathrm{g} / \mathrm{mL}$. The results are plotted between absorbance versus concentration and then a linear regression equation is made and the correlation coefficient value is obtained. From the experimental results, the linear regression equation is $\mathrm{y}=1.09 \times 10^{2}-2.07 \times 10^{2}$ with $\mathrm{r}$ value of 0.9945 (Fig. 2) [15].

Intra-day and Inter-day precision: Intra-day and interday precision of the experiment was conducted to validate the 


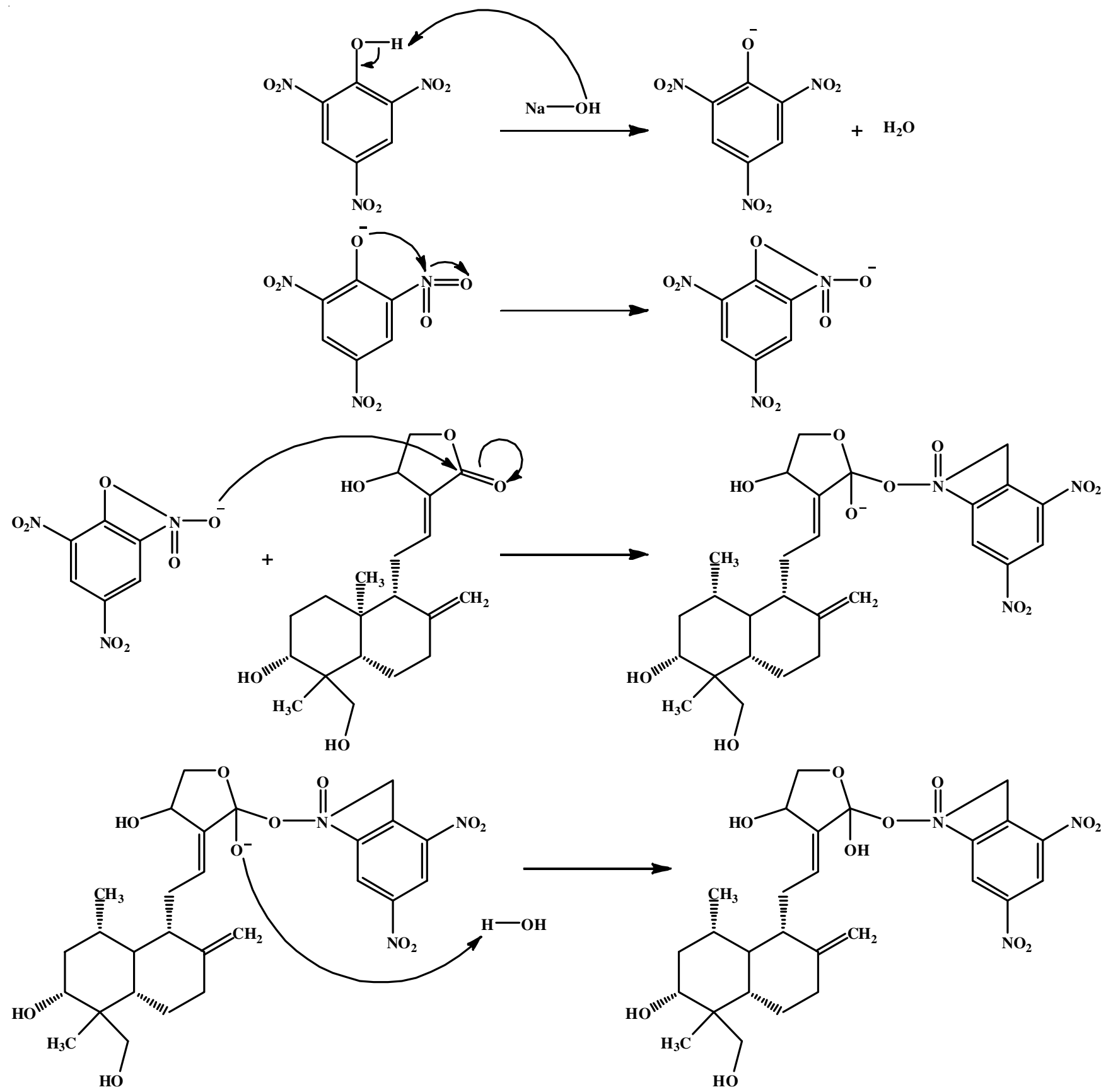

Scheme-I: Mechanism of reaction for the formation of an andrographolide-picric complex

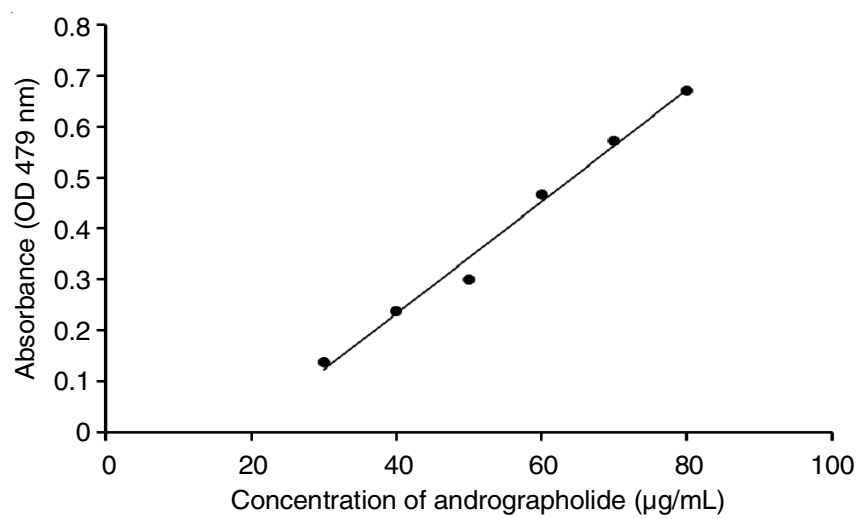

Fig. 2. Standard curve of andrographolide; The standard andrographolide curves were analyzed using a UV-vis spectrophotometer at a wavelength of $479 \mathrm{~nm}, 22 \mathrm{~min}$ OT, with a range of $30-80 \mu \mathrm{g} / \mathrm{mL}$. Linear regression $y=0.0109 x-0.2066$ with $r=0.9945$ experiment. The results showed that the average level of andrographolide is almost similar between each experiment with the values of S.D. of 0.047 and 0.044 , respectively (Table-1).

Accuracy: Evaluation of accuracy is based on percentage of recovery. The value of $\%$ recovery from three levels of concentration between is 97.15 to $104.42 \%$ with $\%$ RSD value of $1.99-2.56 \%$ (Table-2).

Limit of detection (LOD) and Limit of quantification (LOQ): The LOD and LOQ values are found to be 211.6 and $705.4 \mu \mathrm{g} / \mathrm{mL}$. These results indicated that UV-Vis spectrophotometer method can detect andrographolide with the lowest concentration of $211.6 \mu \mathrm{g} / \mathrm{mL}$, besides that it can quantify the andrographolide with the lowest limit of $705.4 \mu \mathrm{g} / \mathrm{mL}$.

A study conducted by Manasa and Suneetha [14] with different reagents and conditions were almost similar with the 


\begin{tabular}{|c|c|c|c|}
\hline \multicolumn{4}{|c|}{$\begin{array}{c}\text { TABLE-1 } \\
\text { INTRA- AND INTER-DAY PRECISION OF } \\
\text { ANDROGRAPHOLIDE }\end{array}$} \\
\hline & $\begin{array}{c}\text { Sample concentration } \\
(\mathrm{mg} / \mathrm{mL})\end{array}$ & Average \pm SD & $\operatorname{RSD}(\%)$ \\
\hline $\begin{array}{l}\text { Intra-day } \\
\text { precision }\end{array}$ & $\begin{array}{l}1.451 \\
1.439 \\
1.549 \\
1.441 \\
1.508 \\
1.526 \\
\end{array}$ & $1.486 \pm 0.047$ & 3.23 \\
\hline $\begin{array}{l}\text { Inter-day } \\
\text { precision }\end{array}$ & $\begin{array}{l}1.489 \\
1.512 \\
1.453 \\
1.526 \\
1.563 \\
1.448 \\
\end{array}$ & $1.499 \pm 0.044$ & 3.06 \\
\hline
\end{tabular}

\begin{tabular}{ccccc}
\multicolumn{5}{c}{ TABLE-2 } \\
\multicolumn{5}{c}{ ACCURACY RESULTS OF ANDROGRAPHOLIDE } \\
\hline $\begin{array}{c}\text { Concentration } \\
\text { level }(\%)\end{array}$ & $\begin{array}{c}\text { Analyte } \\
\text { found } \\
(\mathrm{mg} / \mathrm{mL})\end{array}$ & $\begin{array}{c}\text { Recovery } \\
(\%)\end{array}$ & $\begin{array}{c}\text { Average } \pm \\
\text { SD }\end{array}$ & RSD $(\%)$ \\
\hline \multirow{5}{*}{80} & 1.53 & 100.5 & $99.94 \pm$ & 2.56 \\
& 1.51 & 97.15 & 2.56 & \\
\hline \multirow{2}{*}{100} & 1.54 & 102.08 & & 1.99 \\
& 1.71 & 104.42 & $102.19 \pm$ & \\
\hline \multirow{2}{*}{120} & 1.69 & 101.74 & 2.04 & \\
& 1.68 & 100.4 & & \\
\hline
\end{tabular}

present experiments, which had the LOD and LOQ values of 1 and $3 \mu \mathrm{g} / \mathrm{mL}$, respectively. This is due to the large standard concentration used therefore, the LOD and LOQ values are considered as not good. Based on the results, it can be said that the present method is valid for the determination of andrographolide levels, but it is less sensitive due to the limited LOD and LOQ values. The large LOD and LOQ values can be caused by several factors, besides the use of large standard concentrations, the sensitivity of tools used also affects the LOD and LOQ values which can influence the high LOD and LOQ values. Besides the intervention of other compounds can also interfere with the absorbance value obtained. In this method the compound which might interfere with the absorbance value is $\mathrm{NaOH}$ and picric acid.

\section{Conclusion}

In conclusion, a fast, simple and inexpensive method for detection and quantification of andrographolide concentration in nanoemulsion preparations containing a combination of Andrographis paniculata (Burm f.) Ness. and Phyllanthus niruri $\mathrm{L}$. has been developed. The linear range of standard curve $30-80 \mu \mathrm{g} / \mathrm{mL}$ with $\mathrm{r}=0.9945$ and the accuracy range at 97.15-104.42 \% with RSD value is $2.27 \%$. The precision of intra-day and inter-day were 1.48 and $1.49 \%$, respectively. This validated method is expected to be a reference method for standardization of herbal nanopreparation.

\section{CONFLICT OF INTEREST}

The authors declare that there is no conflict of interests regarding the publication of this article.

\section{REFERENCES}

1. S. Arastehfar, Y. Liu and W.F. Lu, J. Ind. Prod. Eng., 31, 286 (2014); https://doi.org/10.1080/21681015.2014.951407.

2. A.E. Nugroho, M. Andrie, N.K. Warditiani, E. Siswanto, S. Pramono and E. Lukitaningsih, Indian J. Pharmacol., 44, 377 (2012).

3. A. Chaurasia, M.D. Kharya, B. Sharma and P. Roy, J. Complement. Integr. Med., 9, 21 (2012);

https://doi.org/10.1515/1553-3840.1632.

4. X.F. Zhang and B.K.H. Tan, Acta Pharmacol. Sin., 21, 1157 (2000).

5. M. Borhanuddin, M. Shamsuzzoha and A.H. Hussain, Bangladesh Med. Res. Counc. Bull., 20, 24 (1994).

6. P. Radhika, A. Annapurna and N.S. Rao, Res. J. Biotechnol., 7, 43 (2012).

7. A.M. Dandu and N.M. Inamdar, Pak. J. Pharm. Sci., 22, 49 (2009).

8. X.F. Zhang and B.K.H. Tan, Clin. Exp. Pharmacol. Physiol., 27, 358 (2000b); https://doi.org/10.1046/j.1440-1681.2000.03253.x

9. Z.A. Amin, M.A. Abdulla, H.M. Ali, M.A. Alshawsh and S.W. Qadir, J. Sci. Food Agric., 92, 1874 (2012); https://doi.org/10.1002/jsfa.5554.

10. M. Lemus, Y. Ramos, A. Liscano and H. D' Armas, Rev. CientificaFacul. Ciencias Veterinarias, 23, 11 (2013).

11. R.F. de Araújo Júnior, T.P. de Souza, J.G.L. Pires, L.A.L. Soares, A.A. de Araújo, P.R. Petrovick, H.D.O. Mâcedo, A.L.C. de Sá Leitão Oliveira and G.C.B. Guerra, Exp. Biol. Med., 237, 1281 (2012); https://doi.org/10.1258/ebm.2012.012130.

12. L.G. Ranilla, E. Apostolidis and K. Shetty, Phytother. Res., 26, 791 (2012); https://doi.org/10.1002/ptr.3646.

13. M. Da'i, E.R. Wikantyasning, A. Suhendi and I. Hairunisa, Int. J. Pharm. Sci. Rev. Res., 26, 140 (2015).

14. K. Manasa and A. Suneeth, Asian J. Pharm. Anal., 4, 85 (2014).

15. B. Priyambodo, Manajemen Farmasi Industri, Global Pustaka Utama: Yogyakarta, Indonesia (2007) (In Indonesian). 